\title{
Analysis of ENSO simulation biases in FIO-ESM version 1.0
}

\author{
Xingrong Chen ${ }^{1} \cdot$ Huaxia Liao ${ }^{2,3,4} \cdot$ Xiaoyan Lei $^{3} \cdot$ Ying Bao $^{2} \cdot$ Zhenya Song $^{2,3} \mathbb{C}$
}

Received: 17 April 2019 / Accepted: 28 August 2019 / Published online: 3 September 2019

(c) The Author(s) 2019

\begin{abstract}
As the most significant interannual variability in the climate system, El Niño-Southern Oscillation (ENSO) has critical effects on global weather and climate patterns. To simulate and predict ENSO, coupled general circulation models (CGCMs) have become a key tool. However, the accurate simulation of ENSO is still a challenge for CGCMs. The performance of El Niño simulations conducted through FIO-ESM v1.0 is examined based on the outputs of the Coupled Model Intercomparsion Project phase 5 (CMIP5) historical experiments. The results show that FIO-ESM v1.0 suffers from similar common problems to other CMIP5 models, including an eastward shift in the central locations of El Niño, adopting a regular period of roughly 3 years, addressing excessively high amplitude, spurious eastward propagation of El Niño events, and Aborted El Niño events. El Niño composite and mixed layer heat budget analyses indicate that these simulation biases are mainly associated with the mean state biases, including a warm Sea Surface Temperature (SST) bias for the central-eastern Pacific, a cold SST bias for the western and central Pacific, seasonal cycles of SST of the equatorial eastern Pacific, and weaker trade winds. Weaker SST-cloud-shortwave radiation feedback in La Niña events than in El Niño events is what creates spurious ENSO amplitude symmetry in the model. We suggest that the improvement of El Niño simulations may be realized by focusing on the mean state and SST-cloud-shortwave radiation feedback in the tropical region. Specifically, further incremental improvements in the mean state of the tropical Pacific should constitute the first step to realizing more accurate ENSO simulation.
\end{abstract}

Keywords El Niño $\cdot$ FIO-ESM v1.0 · CMIP5 historical experiment · Heat budget

\section{Introduction}

El Niño-Southern Oscillation (ENSO) is the strongest interannual variability and large-scale coupled atmosphere-ocean phenomenon that occurs in the climate system (Philander 1983, 1990; Wang and Picaut 2004; Sarachik and Cane 2010). It affects not only the sea surface temperature (SST), precipitation, and atmospheric circulation in the tropics but

Zhenya Song

songroy@ fio.org.cn

1 National Marine Environmental Forecasting Center, Ministry of Natural Resources, Beijing 100081, China

2 Laboratory for Regional Oceanography and Numerical Modeling, Pilot National Laboratory for Marine Science and Technology, Qingdao 266237, China

3 First Institute of Oceanography, Ministry of Natural Resources, No. 6 Xian-Xia-Ling Road, Qingdao 266061, China

4 South China Sea Institute of Oceanology, Chinese Academy of Sciences, Guangzhou 510301, China also the global weather and climate patterns (e.g., Rasmusson and Wallace 1983; Webster and Yang 1992; Glantz 2001; Alexander et al. 2002; McPhaden and Glantz 2006), such as rainfall over continents, the frequency and intensity of typhoons/hurricanes, the intensity of Madden-Julian oscillation (MJO), the East Asian and global monsoons, the Indian ocean dipole (IOD), the Pacific decadal oscillation (PDO), and the North Atlantic oscillation (NAO), among others phenomena. Therefore, the accurate simulation and prediction of ENSO events is of great importance to weather and climate predictability across the globe.

Due to the complex physical interactions that occur among various atmospheric and oceanic processes, ENSO simulations and predictions are usually carried out by using coupled general circulation models (CGCMs). Significant progress has been achieved, in terms of representations the basic features of ENSO (Bellenger et al. 2014; Flato et al. 2013) since the pioneering work of Manabe and Bryan (1969) adopting a climate model. However, compared to models of the Coupled Model Intercomparison Project phase 3 (CMIP3), CMIP5 models' simulations of ENSO 
properties, including mean SST, amplitude, period, and phase locking, show no significant improvements (Flato et al. 2013; Bellenger et al. 2014). As such, excessively regular and large amplitudes, and spurious phase locking complicate ENSO simulations using CGCMs, which limits our understanding and prediction ability of ENSO events.

FIO-ESM v1.0 was developed by the First Institute of Oceanography and was adopted in the CMIP5 (Qiao et al. 2013). Previous studies showed that FIO-ESM v1.0 generates reasonable simulation results in terms of SST mean states for the tropical regions, eastern tropical Pacific SST seasonal cycles, the IOD, etc. (Qiao et al. 2013; Liu et al. 2014; Song et al. 2014) by incorporating the non-breaking surface wave vertical mixing (hereafter wave-induced mixing) into the model. In particularly, the model exhibits good performance in terms of ENSO diversity (Matveeva et al. 2018), spatial distributions of SST peaks during El Niño events (Graham et al. 2017), relationships between ENSO and the Northern Hemisphere polar region (Roy et al. 2019), and ENSO predictions (Song et al. 2015). However, it still suffers from similar ENSO simulation biases similar to those of other CMIP5 models (Bellenger et al. 2014; Taschetto et al. 2014; Yun et al. 2016). Although there were a number of studies have been conducted on ENSO simulation capabilities using FIO-ESM v1.0, they focused on multi-model mean biases analyses (e.g., Bellenger et al. 2014; Murphy et al. 2015; Graham et al. 2017; Feng et al. 2019) or simulation results assessments for future projections (e.g., Wang et al. 2013; Taschetto et al. 2014; Yun et al. 2016; Xu et al. 2017). A systematic analysis of ENSO simulation biases by FIO-ESM v1.0 has not been done. Therefore, in an effort to better understand the model biases and improve the simulation capabilities, we carefully analyze the simulation biases of ENSO as reflected in FIO-ESM v1.0 in reference to periods, amplitudes, and phase locking.

The remainder of this paper is organized as follows. In Sect. 2, we introduce the datasets and methodology used to analyze El Niño simulation biases. The El Niño simulation evaluation and the corresponding biases analysis are presented in Sect. 3. We provide a summary and discussion in Sect. 4.

\section{Model, datasets and methodology}

\subsection{FIO-ESM v1.0}

FIO-ESM v1.0 was the first earth system model coupled with an ocean surface wave model and employed to conduct the CMIP5 in 2012 (Qiao et al. 2013). It is composed of a coupled physical climate model and a coupled carbon cycle model. In this work, only the results derived from the coupled physical climate model are analyzed. The coupled physical climate model includes Community Atmosphere Model version 3 (CAM3) (Collins et al. 2006), Community Land Model version 3.5 (CLM3.5) (Oleson et al. 2008), Los Alamos National Laboratory sea ice model version 4 (CICE4) (Hunke and Lipscomb 2008), Parallel Ocean Program version 2.0 (POP2.0) (Smith et al. 2010), and MASNUM surface wave model (Yang et al. 2005). The horizontal resolutions of CAM3 (with 26 vertical layers) and CLM3.5 are T42 spectral truncation (approximately $2.875^{\circ}$ ), a nominal $1^{\circ}$ is applied for POP2.0 (with 40 vertical layers) and CICE 4 , and $2^{\circ}$ is used for the MASNUM surface wave model. Further information on FIO-ESM v1.0 can be found in Qiao et al. (2013).

\subsection{Datasets}

The SST data were derived from the ERSST v4.0 at a resolution of $2^{\circ} \times 2^{\circ}$ from 1956 to 2005 (Huang et al. 2015). Ocean temperature data used in this study were obtained through EN4 reanalysis with a horizontal resolution of $1^{\circ} \times 1^{\circ}$ from 1956 to 2005 (Good et al. 2013). Ocean currents and heat flux were obtained from Global Ocean Data Assimilation System (GODAS) datasets at a horizontal resolution of $1^{\circ} \times 0.33^{\circ}$ from 1980 to 2005 (Behringer and Xue 2004). Wind stress was derived from the monthly mean NCEP/NCAR reanalysis dataset at a resolution of T62 from 1956 to 2005 (Kalnay et al. 1996). For convenience, the observational and reanalysis data are all referred to as "observations" in this work.

Three CMIP5 experiments for the historical simulation (named r1i1p1, r2i1p1, and r3i1p1) of FIO-ESM v1.0 were conducted from January 1 for 701a, 651a, and 401a of the PiControl experiment, respectively. The 3 realizations only differ in terms of initial conditions, which have almost no effect on the ENSO results (Song et al. 2012a). Therefore, the first realization of the FIO-ESM v1.0 historical experiment (r1i1p1) conducted from 1956 to 2005 is analyzed in this work. The horizontal resolution of ocean variables, including temperature, currents, wind stress, and heat flux, is at about approximately $1.1^{\circ}$ in longitude and $0.3^{\circ}$ in latitude.

The model simulation and observation data are monthly mean and interpolated to a $1^{\circ} \times 1^{\circ}$ grid. For each field, an anomaly field was produced by subtracting the long-termaveraged seasonal cycle at each grid point. Table 1 provides a summary of the data used in this study.

\subsection{Mixed-layer heat budget}

The mixed-layer heat budget proposed by Huang et al. (2010) is used to analyze El Niño events in this study. The mixed-layer temperature equation is written as follows:

$T_{t}=Q_{u}+Q_{v}+Q_{w}+Q_{z z}+Q_{q}$

where $T_{t}$ is the mixed-layer temperature tendency $(\partial \mathrm{T} / \partial \mathrm{t})$; $Q_{u}$ represents the zonal advection contribution $(-\mathrm{u} \partial \mathrm{T} / \partial \mathrm{x})$; 
Table 1 Features of the datasets used in this study

\begin{tabular}{llll}
\hline & Field & Resolution & Record length \\
\hline ERSST v4.0 & SST & $2^{\circ} \times 2^{\circ}$ & $1956-2005$ \\
EN4 reanalysis & Ocean temperature & $1^{\circ} \times 1^{\circ}$ & $1956-2005$ \\
GODAS & Ocean current & $1^{\circ} \times 0.33^{\circ}$ & $1980-2005$ \\
& Heat flux & & \\
$\begin{array}{c}\text { NCEP/NCAR Rea- } \\
\text { nalysis }\end{array}$ & Wind stress & T62 & $1956-2005$ \\
$\begin{array}{l}\text { FIO-ESM v1.0 } \\
\text { Ocean temperature }\end{array}$ & $1^{\circ} \times 0.3^{\circ}$ & $1956-2005$ \\
& $\begin{array}{l}\text { Ocean current } \\
\end{array}$ & & \\
& Heat flux & & \\
& Wind stress & & \\
\hline
\end{tabular}

$Q_{v}$ represents the meridional advection contribution $(-\mathrm{v} \partial \mathrm{T} / \partial \mathrm{y}) ; Q_{w}$ represents the vertical entrainment contribution $\left(-w_{e} \partial \mathrm{T} / \partial \mathrm{z}\right) ; Q_{z z}$ represents the vertical diffusion contribution $\left(Q_{\text {diff }} /\left(\rho c_{p} h\right)\right)$; and $Q_{q}$ represents the net surface heat flux contribution $\left(Q_{\text {surf }} /\left(\rho c_{p} h\right) \bigcup_{i=1}^{n} X_{i}\right)$. Horizontal diffusion is ignored in this study. And $\mathrm{T}$ is temperature; $\mathrm{u}$ and $\mathrm{v}$ are zonal and meridional velocity, respectively; $w_{e}$ is the entrainment velocity across the bottom of the mixed layer; $Q_{\text {diff }}$ is the diffusive heat flux at the bottom of the mixed layer; $Q_{d i f f}$ is net surface heat flux; $\rho$ and $c_{p}$ are the density and heat capacity of seawater, respectively; and $h$ is the mixed layer depth.

Then, the equation for anomalous mixed-layer temperature becomes

$T_{t}^{\prime}=Q_{u}^{\prime}+Q_{v}^{\prime}+Q_{w}^{\prime}+Q_{z z}^{\prime}+Q_{q}^{\prime}+E^{\prime}$

where the prime denotes the anomaly, and $E^{\prime}$ is the residual, including horizontal diffusion and the sum of values that cannot be calculated from monthly mean data. Further details on ways to calculate these terms can be found in Huang et al. (2010).

Equation (2) can be rewritten as:

$T_{t}^{\prime}=F+E^{\prime}$

where $F$ (called forcing) is the sum of $Q_{u}^{\prime}, Q_{v}^{\prime}, Q_{w}^{\prime}, Q_{z z}^{\prime}$, and $Q_{q}^{\prime}$. To identify the closure of the mixed-layer heat budget, the correlation coefficient and root mean square error (RMSE) between $T_{t}^{\prime}$ and $F$ are calculated using model outputs. Correlation coefficients of the Niño 3 (averaged over $90^{\circ}-150^{\circ} \mathrm{W}$, $5^{\circ} \mathrm{S}-5^{\circ} \mathrm{N}$ ), Niño 3.4 (averaged over $170^{\circ}-120^{\circ} \mathrm{W}, 5^{\circ} \mathrm{S}-5^{\circ} \mathrm{N}$ ), and Niño 4 (averaged over $160^{\circ} \mathrm{E}-150^{\circ} \mathrm{W}, 5^{\circ} \mathrm{S}-5^{\circ} \mathrm{N}$ ) regions are valued at $0.96,0.89$, and 0.84 , respectively, while the RMSEs for these regions are $0.08,0.11$, and $0.10^{\circ} \mathrm{C} /$ month, respectively. This indicates that the mixed-layer heat budget of Eq. (2) exhibits closure, which ensures that the following results are credible and robust. Furthermore, the values of simulated Niño 3 index are larger than them of Niño 3.4 and Niño 4 indexes (figure not shown), which indicates that there is only traditional El Niño events (called EP El Niño) in the FIO-ESM v1.0. Therefore, the Niño 3 region is selected to represent El Niño events given its strong heat budget closure value. It should be noted that the mixed layer depth is defined as the depth at which the ocean temperature deviates by $0.5{ }^{\circ} \mathrm{C}$ from the SST and it is set as $50 \mathrm{~m}$ for the mixed layer heat budget to achieve more closure.

\section{Simulation biases analysis}

\subsection{Simulated El Niño results vs. observations}

Figure 1 shows the power spectra and time series of the Niño 3 SST anomaly (SSTA) during the period from 1956 to 2005 for both observation and FIO-ESM v1.0 data. In this work, the Niño 3 SSTA is the monthly anomaly relative to the climatology of 1956-2005, which echo the mixedlayer temperature anomaly (figure not shown). FIO-ESM v1.0 failed to capture the period of El Niño events. Diverging from the observations made over a broad spectral range (Fig. 1a), there is only one sharp peak of roughly three years from FIO-ESM v1.0 (Fig. 1b). Standard deviations of the Niño 3 index taken from the observations and FIO-ESM v1.0 from 1856 to 2005 are valued at 0.81 and 1.55 , respectively, suggesting the ENSO events was simulated as too regular and too strong.

Next, El Niño (red shading in Fig. 1c, d) and La Niña events (blue shading in Fig. 1c, d) are identified based on a threshold of $\pm 0.5^{\circ} \mathrm{C}$ for at least 5 consecutive overlapping 3-month periods of the Niño 3 SSTA. From 1956 to 2005, there were 16 El Niño events and 12 La Niña events according to the model simulation (Fig. 1d), while there were only 12 El Niño events and $10 \mathrm{La}$ Niña events according to the observations (Fig. 1c). When the El Niño occurs for two consecutive years, it is counted as one El Niño event, and the very weak El Niño events are not counted in this work.

The Niño 3 SSTA is shown in Fig. 2 for the 12 observed and 16 simulated El Niño events from 1956 to 2005 . For individual El Niño events, 10 out of the 12 observed events had peak amplitude between $1.0{ }^{\circ} \mathrm{C}$ and $2.0^{\circ} \mathrm{C}$; two events (occurring in 1982/83 and 1997/98) show peaks reaching $3{ }^{\circ} \mathrm{C}$ (Fig. 2a). However, 14 of the 16 simulated events present peak amplitudes of greater than $1.5^{\circ} \mathrm{C}$, and more than half range from 2.0 to $3.0^{\circ} \mathrm{C}$ (Fig. 2b). In addition to the fact that the simulated events present excessively high amplitudes, the timing of the simulated peaks is also inconsistent with that of the observed. In general, the peak amplitude is phase-locked to the boreal winter (hereafter refer to as winter El Niño) from the observations (Fig. 2a). Only one El Niño event (occurring during 1987; Fig. 2a, cyan line) was 
Fig. 1 Power spectra of the Niño 3 SSTA of 1956-2005 from (a) ERSST and (b) FIOESM v1.0 historical experiment data, and time series of the Niño 3 index from (c) ERSST and (d) FIO-ESM. Warm (red) and cold (blue) periods shown in (c) and (d) are based on a threshold of $\pm 0.5^{\circ} \mathrm{C}$ for the Oceanic Niño Index (ONI) from the CPC (a)

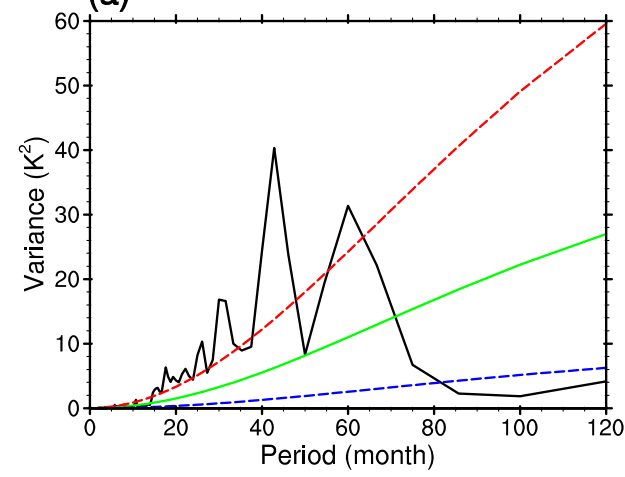

(b)

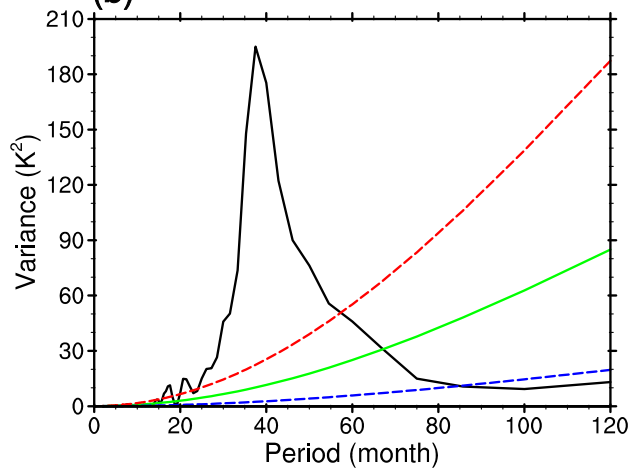

(c)

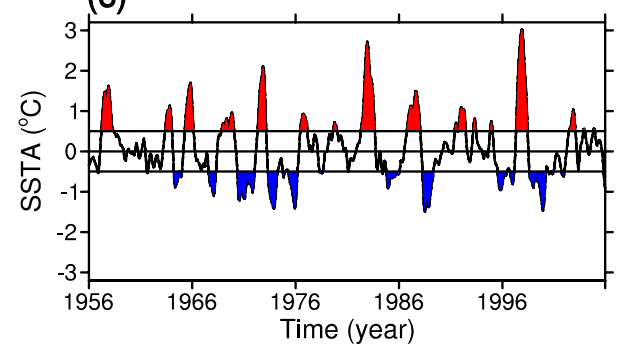

(d)

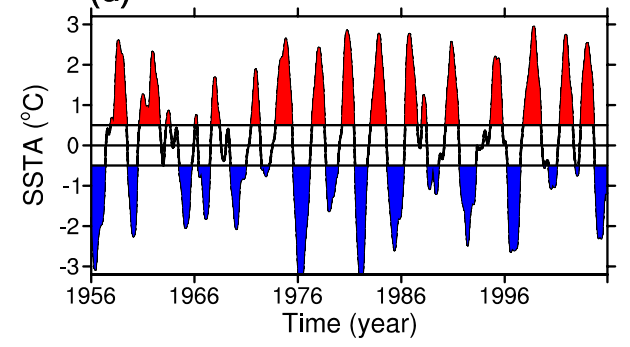

(a) ERSST

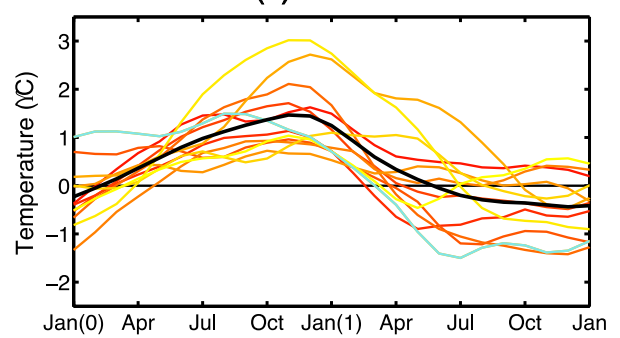

(b) FIO-ESM

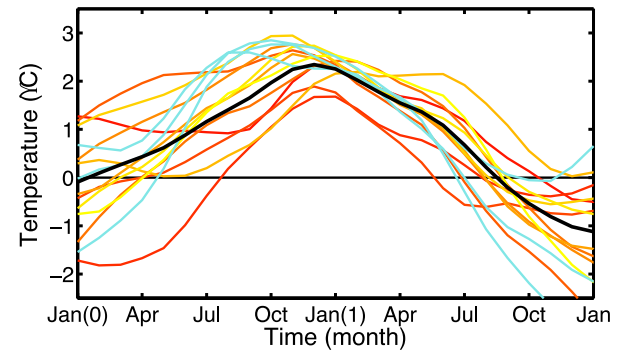

Fig. 2 Evolution of the Niño 3 SSTA for the El Niño events taken from (a) ERSST and (b) FIO-ESM v1.0 historical experiment data. The cyan line denotes individual Aborted El Niño events, the black line shows the composite of winter El Niño events, and other colored lines represent individual winter El Niño events

phase-locked to September (McPhaden et al. 1990; hereafter referred to as Aborted El Niño) in observations. In contrast, three out of the 16 simulated El Niño events were Aborted El Niño events (Fig. 2b, cyan line), representing a common problem encountered with CMIP5 models (Bellenger et al. 2014).
The El Niño composite, which aligns all the El Niño events according to their peak phases that are reset to be January of year 1 after the alignment, is a commonly used to analyzed the evolution process of El Niño events. It should be noted that the El Niño composite for Aborted events is the average for the same month to better illustrate the different processes between winter and Aborted El Niño events. The SSTA of the winter El Niño composite excluding the three Aborted El Niño events is shown in Fig. 3. In the El Niño composite spatial distribution (Fig. 3), the positive SSTA runs from the Peruvian coast to $180^{\circ}$ in both the observations and FIO-ESM v1.0 (Fig. 3a, shading). This indicates that the structure of simulated El Niño events agrees well with that of the observations zonally, although the simulated maximum positive SSTA $\left(110^{\circ} \mathrm{W}\right)$ is centered east of that observed $\left(125^{\circ} \mathrm{W}\right)$ and is larger than that observed. However, the area covered by simulated El Niño event is too narrower than that observed (Fig. 3a, contour) meridionally. Moreover, as the simulated positive SSTA appeared in the centraleastern equatorial Pacific (near $150^{\circ} \mathrm{W}$; Fig. 3b, shading), the El Niño event developed with eastward propagation, which is not consistent with the observations (Fig. 3b, contour).

\subsection{El Niño biases in the model}

The analysis results of simulated El Niño events given in Sect. 3.1 illustrate that FIO-ESM v1.0 can capture basic features of El Niño events but suffers similar simulation problems as those of other CMIP5 models, such as an eastward shifting of the central locations of El Niño events, having regular periods of roughly 3 years, excessively high 
(a) SSTA Composite $\left({ }^{\circ} \mathrm{C}\right)$

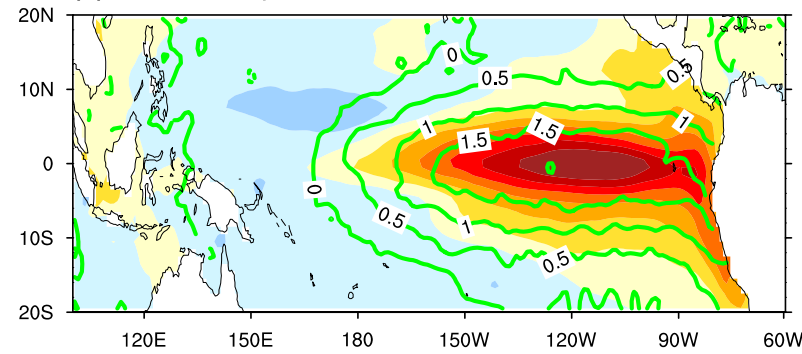

(b) SSTA Composite $\left({ }^{\circ} \mathrm{C}\right)$

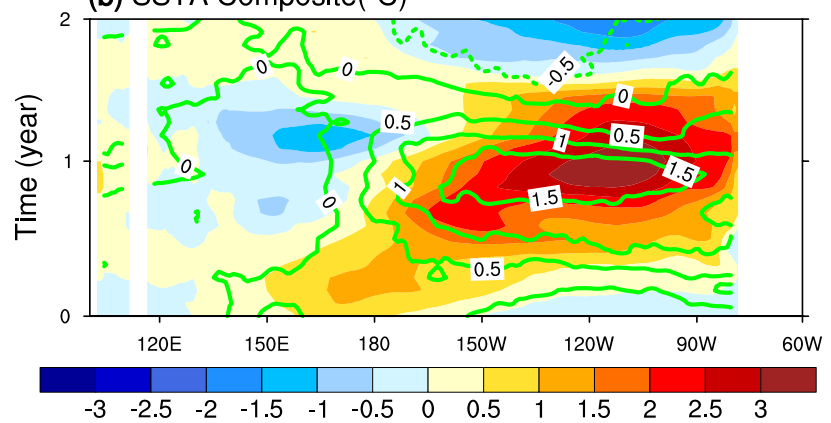

Fig. 3 Winter El Niño composite from 1956 to 2005. a SST anomaly spatial distribution for December, and (b) evolution of anomalies along the equator $\left(2^{\circ} \mathrm{S}-2^{\circ} \mathrm{N}\right)$. ERSST and FIO-ESM v1.0 historical experiment data are represented by contours and shadings, respectively

amplitudes, spurious eastward propagation, and Aborted El Niño events. In the following sections, we specifically analyze these simulated biases.

\subsubsection{Eastward shifting of the central locations of El Niño events}

The central location of an El Niño event is associated with the tropical SST mean state. From 50 years averaged SST, the simulated $28{ }^{\circ} \mathrm{C}$ isotherm of the equatorial Pacific SST extends to $170^{\circ} \mathrm{W}$ (Fig. $4 \mathrm{~b}$ ), which is consistent with the distribution observed (Fig. 4a) at the equator. However, the simulated cold tongue is narrower and warmer than that ovserved. Especially in the central-eastern equatorial Pacific, there are more than $1^{\circ} \mathrm{C}$ warm SST bias and weaker trade winds in FIO-ESM $v 1.0$ (Fig. 4c) due to the waveinduced vertical mixing (Song et al. 2012b), whereas other the CMIP5 models tend to present a cold bias. In addition, the positioning of Walker circulation shifts eastward. Therefore, the simulated anomalous westerly winds are stronger (Fig. 5b) than those observed (Fig. 5a) and tend to eastward when an El Niño event is in the onset phase. Meanwhile, through the Bjerknes positive feedback, the stronger westly winds increase the positive SSTA in the east equatorial Pacific (Fig. 5c, d), which will also enhance the westerly winds and the eastward tendency of central locations of Walker circulation. Eventually, the central location of an (a) SST and Wind Stress (Obs)

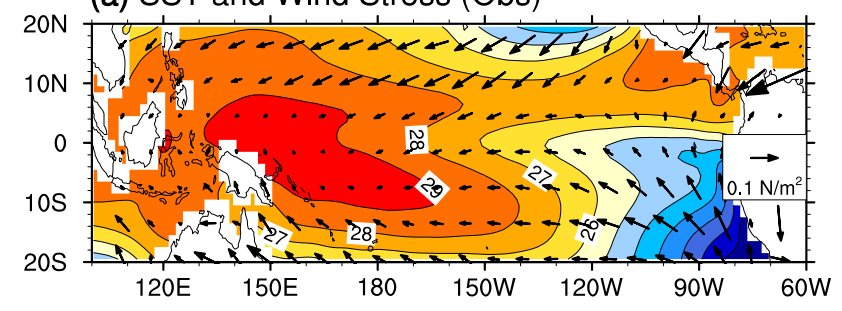

(b) SST and Wind Stress (FIO-ESM)

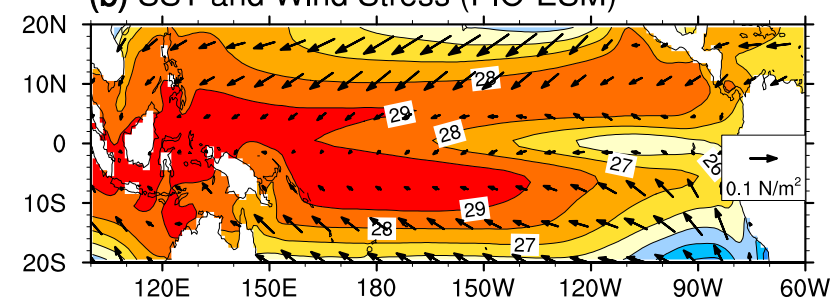

(c) SST and Wind Stress biases (FIO-ESM - Obs)

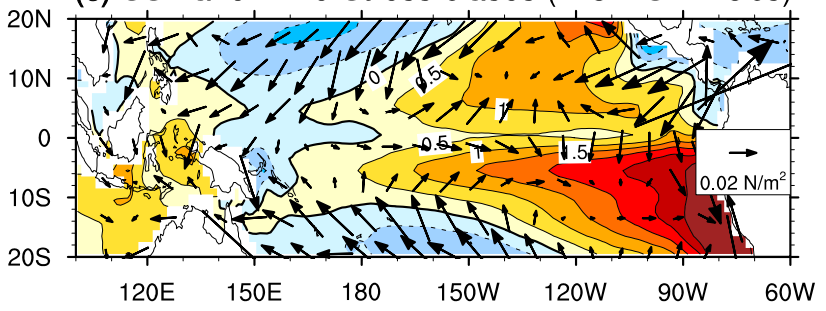

(d) MLD bias (FIO-ESM - Obs)

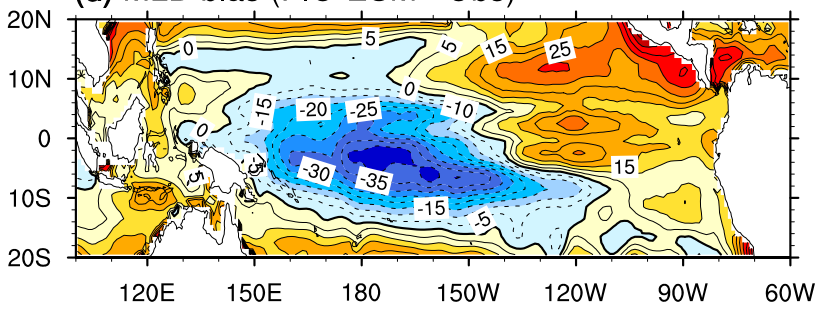

Fig. 4 Climatological (a) SST (ERSST) and wind stress (NCEP) from the observation, (b) SST and surface wind from FIO-ESM v1.0 data, (c) SST and wind stress biases (FIO-ESM minus observation), and (d) mixed-layer depth biases (FIO-ESM minus observation) of the tropical Pacific from 1956 to 2005. Mixed-layer depth calculated from EN4 is here regarded as observation. Units of SST, wind stress, and mixed-layer depth are set as ${ }^{\circ} \mathrm{C}, 0.1 \mathrm{~N} / \mathrm{m}^{2}\left(0.02 \mathrm{~N} / \mathrm{m}^{2}\right.$ in c) and $\mathrm{m}$, respectively

El Niño event shifts eastward during the development stage (Fig. 5d).

The tropical Pacific has begun to experience a new type of El Niño frequently occurring over during the last decade referred to as the central Pacific (CP) El Niño. Unfortunately, there is only EP El Niño events but no CP El Niño events in FIO-ESM v1.0 during 1956-2005. The simulation capacities of the coupled models for two types of El Niño are strongly affected by the model biases (e.g., Zheng et al. 2015; Fang et al. 2015). For FIO-ESM v1.0, the lack of CP El Niño events is mainly attributable to the eastward shifting of the 
(a) U-Wind Stress, $0.01 \mathrm{~N} / \mathrm{m}^{2}, 2 \mathrm{~S}-2 \mathrm{~N}$, Composite of Observation

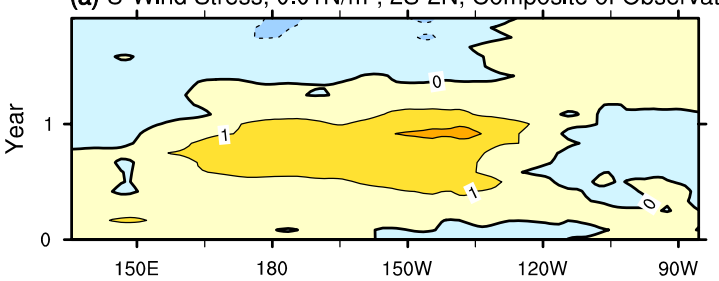

(c) Mixed layer temperature, ${ }^{\circ} \mathrm{C}$

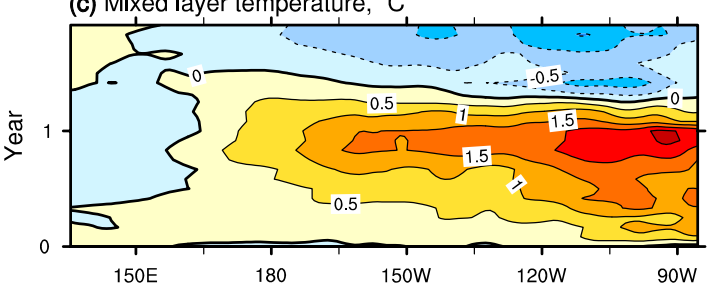

(e) $\mathrm{U}, \mathrm{cm} / \mathrm{s}$
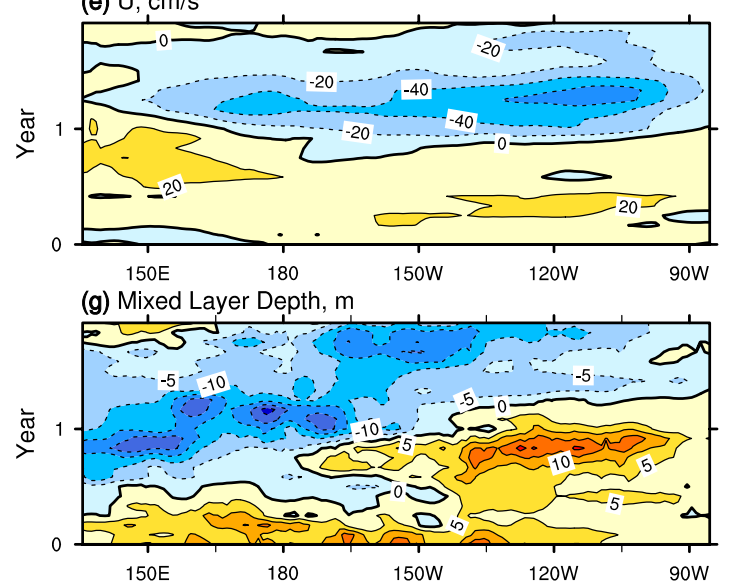

Fig. 5 Anomalous winter El Niño composite along the equator $\left(2^{\circ} \mathrm{S}-2^{\circ} \mathrm{N}\right.$ average). a, b Denote zonal wind stress, (c) and (d) denote the SSTA, (e) and (f) denote zonal oceanic currents, and (g) and (h) denote mixed-layer depths. Counter intervals are set to $0.01 \mathrm{~N} / \mathrm{m}^{2}$ in

central locations of El Niño events, which leads simulated El Niño events to occur in the equatorial eastern Pacific.

\subsubsection{Regular periods of approximately 3 years}

The ENSO period is controlled by two processes: zonal advective feedback and thermocline feedback. Zonal advective feedback $\left(u^{\prime} \bar{T}_{x}\right.$, subscripts $x, y$, and $z$ denote partial derivatives) refers to the effect of zonal currents forced by anomalous zonal wind stress on the mean zonal temperature gradient, which leads to a $20-40$-month period. Thermocline feedback $\left(\bar{w} T_{z}^{\prime}\right)$ refers to the effect of changes in the thermocline slope forced by anomalous basin-wide zonal wind stress on subsurface temperatures via mean upwelling, which leads to a 50-70-month period.

As discussed in Sect. 3.2.1, the warm SST bias in the central-eastern Pacific enhances the simulated anomalous westerly winds in the onset phase. This enhanced anomalous westerly wind strengths the anomalous zonal current, (b) U-Wind Stress, $0.01 \mathrm{~N} / \mathrm{m}^{2}, 2 \mathrm{~S}-2 \mathrm{~N}$, Composite of FIO-ESM

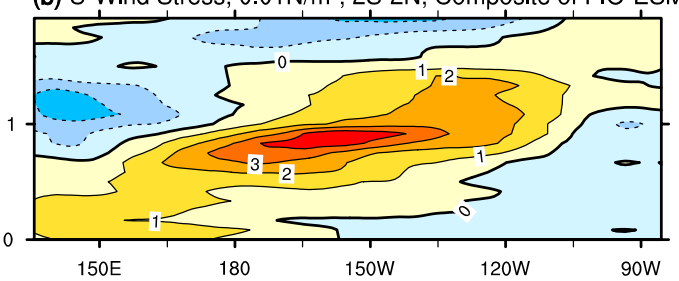

(d) Mixed layer temperature, ${ }^{\circ} \mathrm{C}$
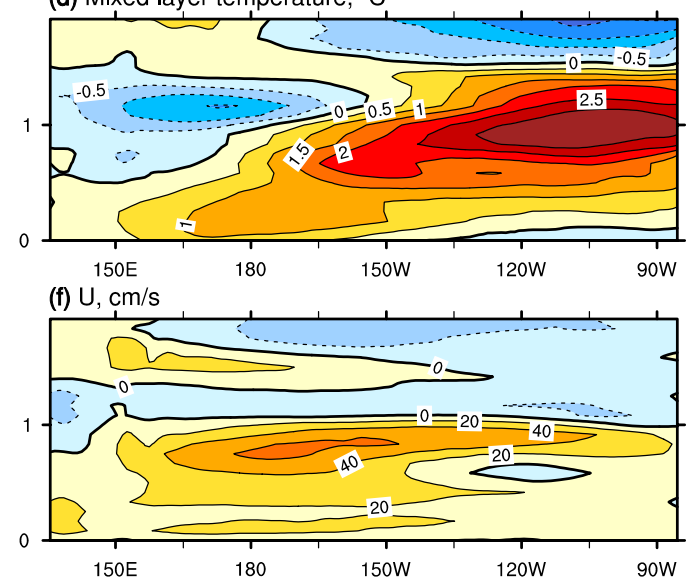

(h) Mixed Layer Depth, $\mathrm{m}$

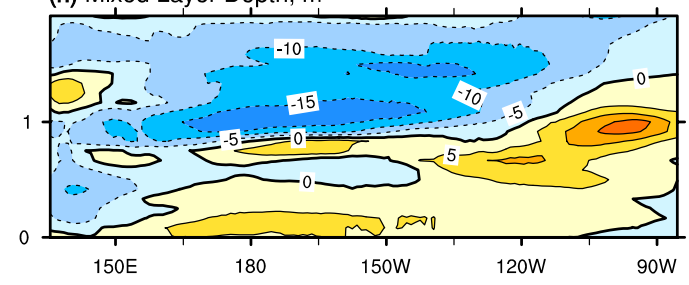

(a) and (b), to $0.5{ }^{\circ} \mathrm{C}$ in (c) and (d), to $20 \mathrm{~cm} / \mathrm{s}$ in (e) and (f), and to $5 \mathrm{~m}$ in (g) and (h). Data shown in the left and right columns are taken from the observations and FIO-ESM v1.0 historical experiment data, respectively

reinforcing the zonal advective feedback (Figs. 5e, f) while the warm SST bias reduces the zonal gradient. Meanwhile, the simulated mixed-layer depth anomaly (Fig. 5h) is lower than that observed (Fig. 5g) due to a deeper climatological mixed-layer depth (Fig. 4d) in FIO-ESM v1.0, which reduces the thermocline feedback. This indicates that zonal advective feedback, leading to high-frequency El Niño events plays a more important role in FIO-ESM v1.0. A further analysis of mixed-layer heat budgets presented in the following paragraph verifies this hypothesis.

Figure 6 shows the mixed-layer heat budget of El Niño events and its decomposition. As vertical diffusion is much smaller than the other terms, it is not decomposed and not included in the figure. Normally, the thermocline feedback is stronger than the zonal advective feedback according to observations. However, although the simulated thermocline feedback ( $\bar{w} T_{z}^{\prime}$; Fig. 6d, red line) is stronger than the zonal advective feedback $\left(u^{\prime} \bar{T}_{x}\right.$; Fig. 6 b, blue line $)$ in the El Niño onset phase $(\operatorname{Jan}(0)$ to $\operatorname{Mar}(0))$ and in the first stage of the 

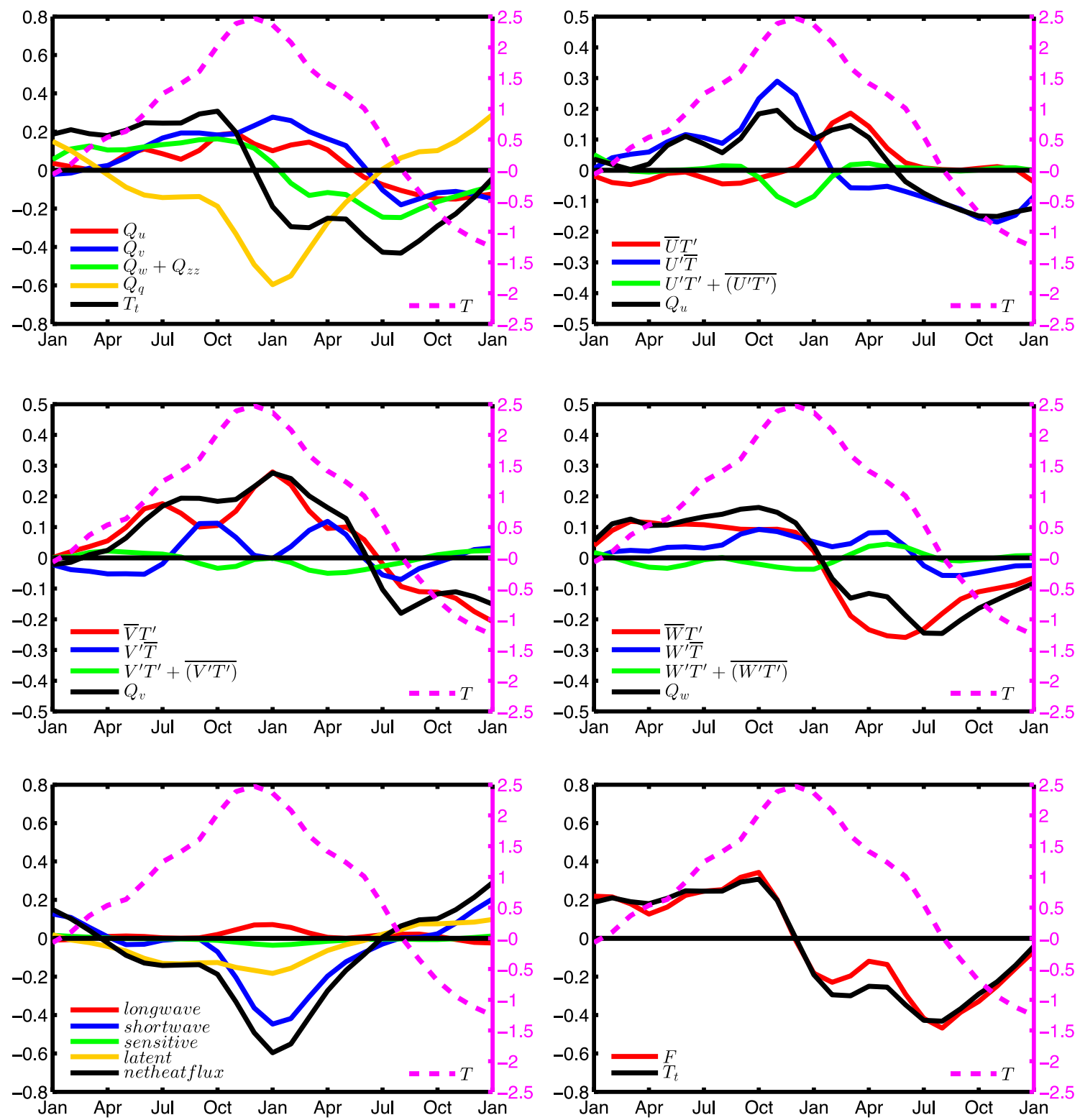

Fig. 6 Anomalous heat budget of the winter El Niño composite of the Niño 3 region $\left(90^{\circ}-150^{\circ} \mathrm{W}, 5^{\circ} \mathrm{S}-5^{\circ} \mathrm{N}\right)$. a Heat budget $\left({ }^{\circ} \mathrm{C} /\right.$ month $)$. Decomposition of (b) zonal advection, (c) meridional advection, (d)

vertical advection and diffusion, (e) net surface heat flux, and (f) heat budget closure. Temperature is plotted on the scale of the right axis

development phase $(\operatorname{Mar}(0)$ to $\operatorname{Jun}(0))$ due to the shallow climatological mixed-layer depth related to the cold SST biases in the western and central Pacific, zonal advective feedback increases to almost the same level $\left(0.2{ }^{\circ} \mathrm{C} /\right.$ month $)$ of thermocline feedback during latter development phase $(\operatorname{Jul}(0)$ to $\operatorname{Oct}(0))$ due to enhanced anomalous zonal currents. During the mature phase $(\operatorname{Nov}(0)$ to $\operatorname{Jan}(1))$, zonal advective feedback reaches $2.6{ }^{\circ} \mathrm{C} /$ month, exceeding levels of thermocline feedback. The results of mixed-layer heat budget results demonstrate that simulated zonal advective feedback dominates the development and mature phases while simulated thermocline feedback plays an important role in the
El Niño onset phase. In other words, El Niño events reflect the combined modes of two feedbacks while zonal advective feedback is slightly stronger in FIO-ESM v1.0. Thus, the simulated ENSO period spans roughly 3 years, which is consistent with the conceptual model results (Jin 1997) but not with the observations.

\subsubsection{Excessively large amplitudes and spurious eastward propagation}

Three processes primarily contribute to the larger amplitude of El Niño events in FIO-ESM v1.0. The first relates 
the warmer SST bias for the equatorial Pacific amplified by the Bjerknes positive feedback as discussed in Sect. 3.2.1. The second reflects to warmer water transport, including stronger simulated zonal advective feedback transporting warmer water from the western Pacific (Fig. 6b, blue line), and meridional transport (Fig. 6c) from the south-eastern and north-eastern Pacific off the equator with a warm SST bias (Fig. 4c). The third relates to the Ekman feedback $\left(w^{\prime} \bar{T}_{z}\right.$; Fig. 6d, blue line), which refers to the effect of anomalous wind-driven upwelling acting on the mean vertical temperature gradient. Upwelling in the eastern equatorial Pacific transports warmer water from the subsurface because the simulated climatological mixed-layer depth is deeper than that observed. Of these three processes, the Ekman feedback effect plays a minimal role. It should be noted that the effects of warmer water transport and Ekman feedback on the SSTA are also amplified by the Bjerknes positive feedback. Surface heat flux feedback, mainly through SSTcloud-shortwave radiation (Lloyd et al. 2012) and WindEvaporation-SST (Xie and Pahilander 1994) feedbacks reflects negative feedback, which always mitigate change in amplitude. In summary, the warmer mean state leads to stronger El Niño events.

As discussed in Sect. 3.2.2, the El Niño events reflect the combined modes of zonal advective feedback and thermocline feedback in FIO-ESM v1.0. Specifically, thermocline feedback is the dominant process in the El Niño onset phase $(\operatorname{Jan}(0)$ to $\operatorname{Mar}(0))$ and in the first 3 months of the development phase $(\operatorname{Apr}(0)$ to $\operatorname{Jun}(0))$ because of the shallow climatological mixed-layer depth related to a cold SST bias in the western and central equatorial Pacific. The time lag between thermocline feedback and zonal advective feedback is 6 months according to in FIO-ESM v1.0 data, which is longer than that observed from the observations. Therefore, the simulated El Niño events tend to show the eastward propagation driven by the thermocline feedback; and the eastward shift in the central locations of El Niño events also contributes to the eastward propagation.

\subsubsection{Aborted El Niño events}

The frequency of Aborted El Niño events from 1956 to 2005 is measured as $18.8 \%$ (three out of 16) in FIO-ESM $\mathrm{v} 1.0$, which is greater than that shown by the observations (8.3\%, one out of 12$)$. Clearly, the mature phase of an El Niño events tends to occur in the summer season in FIOESM, echoing that shown by other CMIP5 models (Bellenger et al. 2014). The observed summer El Niño event observed in 1987 occurred in the second year of an El Niño event that persisted for two consecutive years from 1986 to 1988 (Fig. 1c), and the rate of SSTA increase was almost the same as other El Niño events $\left(0.1^{\circ} \mathrm{C} /\right.$ month $)$ in the development phase (Fig. 2a; $\operatorname{Apr}(0)$ to $\operatorname{Aug}(0)$ ). However, the
SSTA of simulated Aborted El Niño events (Fig. 2b, cyan line) began from a neutral or La Niña conditions and then showed a rapid increase in values (average rate of close to $0.60{ }^{\circ} \mathrm{C} /$ month) to the strongest El Niño event relative to the simulated winter El Niño events $\left(0.23{ }^{\circ} \mathrm{C} /\right.$ month $)$ and to observations of the development phase; this suggests that the mechanisms of Aborted El Niño events reflected in the model differ from those observed. And we also found that Aborted El Niño events are stronger than the winter El Niño events (Fig. 2b), and the amplitudes of the winter El Niño events with peaks occurring in $\operatorname{Nov}(0)$ or $\operatorname{Dec}(0)$ were also larger than those with peaks occuring in Jan(1). This indicates that the mature phase appears earlier on and that the intensity of ENSO is stronger in FIO-ESM v1.0.

Figure 7 shows the heat budget of the winter (blue bar) and Aborted (red bar) El Niño events composites for the development phase of winter El Niño events $(\operatorname{Apr}(0)$ to $\operatorname{Jul}(0))$ and the decay phase of Aborted El Niño events $(\operatorname{Sep}(0)$ to $\operatorname{Dec}(0))$. Note that the period running from $\operatorname{Sep}(0)$ to $\operatorname{Dec}(0)$ is the development phase for the winter El Niño events. The rate of SSTA increase reached almost $0.60{ }^{\circ} \mathrm{C} /$ months from $\operatorname{Apr}(0)$ to $\operatorname{Jul}(0)$ during the Aborted El Niño events (Fig. 7a, red bar), reaching nearly twice the value for the winter El Niño events (Fig. 7a, blue bar). This high rate of increase is mainly attributable due to zonal advective feedback $\left(u^{\prime} \bar{T}_{x}\right)$, climatological meridional current transport $\left(\bar{v} T_{y}^{\prime}\right)$, thermocline feedback $\left(\bar{w} T_{z}^{\prime}\right)$, and Ekman feedback $\left(w^{\prime} \bar{T}_{z}\right)$. Heat flux through Wind-Evaporation-SST ((Xie and Pahilander 1994) and SST-cloud-shortwave (Lloyd et al. 2012) feedbacks always mitigates changes in SST. Thus,
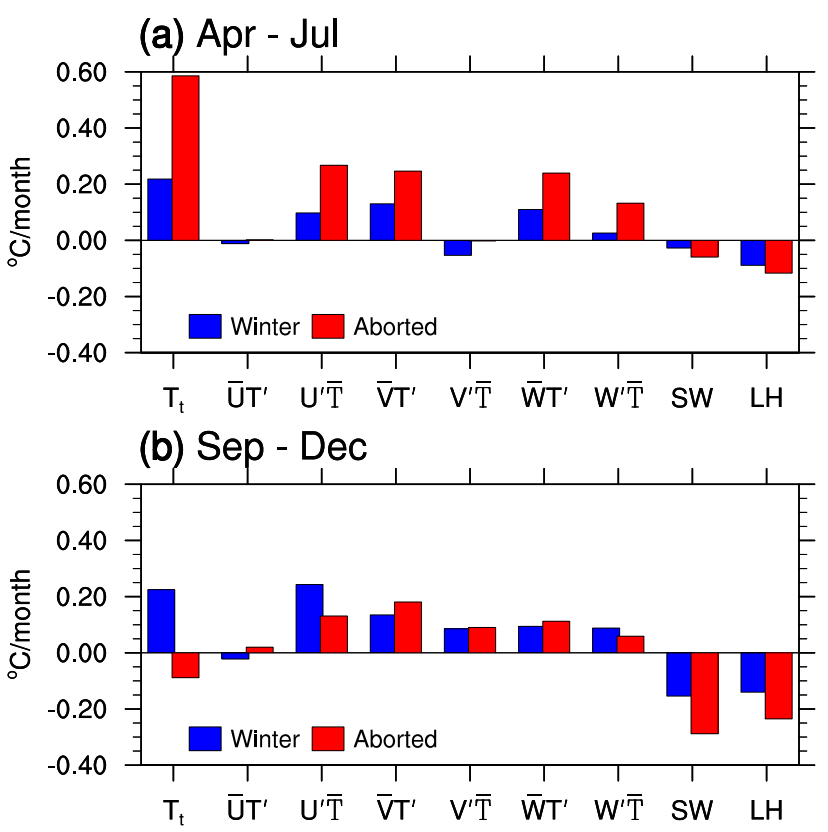

Fig. 7 Anomalous heat budgets of the winter and Aborted El Niño composites. a April-July, and (b) September-December 
the SSTA reached a warm peak before the winter and then decayed due to the negative heat flux feedback.

The mechanisms of phase-locking behavior reflected in both observation and model are complex, which are related to weather noise (Chang et al. 1996; Jin 1996; Blanke et al. 1997), linear interactions (Jin 1996) and nonlinear interactions (Neelin et al. 2000) between El Niño inherent cyclic and seasonal cycles. The above analysis of heat budgets (Fig. 7) indicates that Aborted El Niño events are associated with two biases in FIO-ESM v1.0. The first relates to a warm SST bias over tropical Pacific SST (Fig. 2) similar to other CMIP5 models, which is referred to as the double ITCZ (InterTropical Convergence Zone) problem. Similar to other CMIP5 models, FIO-ESM v1.0 also surfers from the double ITCZ problem. An excessively strong and too zonal Southern Convergence Zone can enhance the climatological meridional current transport and can tend to trigger an Aborted El Niño event (Guilyardi et al. 2003; Zheng and $\mathrm{Yu}$ 2007). The second relates to the weaker seasonal cycle of eastern equatorial Pacific SST (Taschetto et al. 2014). As shown in Fig. 8, the simulated amplitude of the seasonal SST cycle over the eastern equatorial Pacific is smaller than that observed and there are the cold/warm SST bias in the first/second half of the year. The cold SST bias related to the simulated weaker annual cycle tends to trigger a stronger SSTA in the onset phase. Therefore, the SSTA (Fig. 9a), anomalous mixed-layer depth (Fig. 9c), anomalous zonal wind stress (Fig. 9e), anomalous zonal ocean current (Fig. 9g), and anomalous vertical velocity (Fig. 9i) of Aborted El Niño events are greater than those (Figs. 9b, d, f, h, j) of winter El Niño events in the onset phase, leading to stronger zonal advective, thermocline and Ekman feedbacks during an the Aborted El Niño event.
Fig. 8 SST seasonal cycle along the equator $\left(2^{\circ} \mathrm{S}-2^{\circ} \mathrm{N}\right.$ average) from 1956 to 2005 taken from (a) ERSST, (b) FIO-ESM v1.0, (c) FIO-ESM v1.0 minus ERSST data. The annual mean of this period has been removed

\section{(a) ERSST}

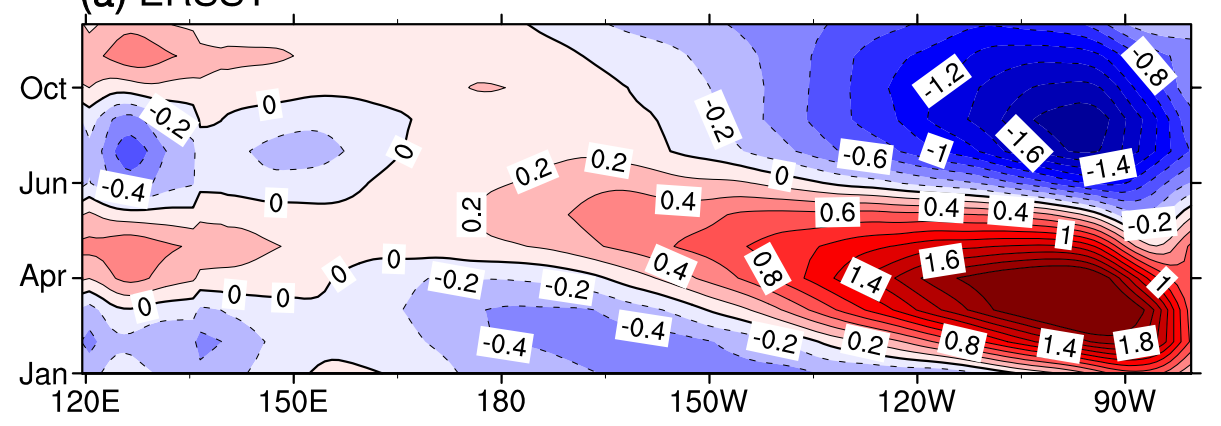

(b) FIO-ESM v1.0

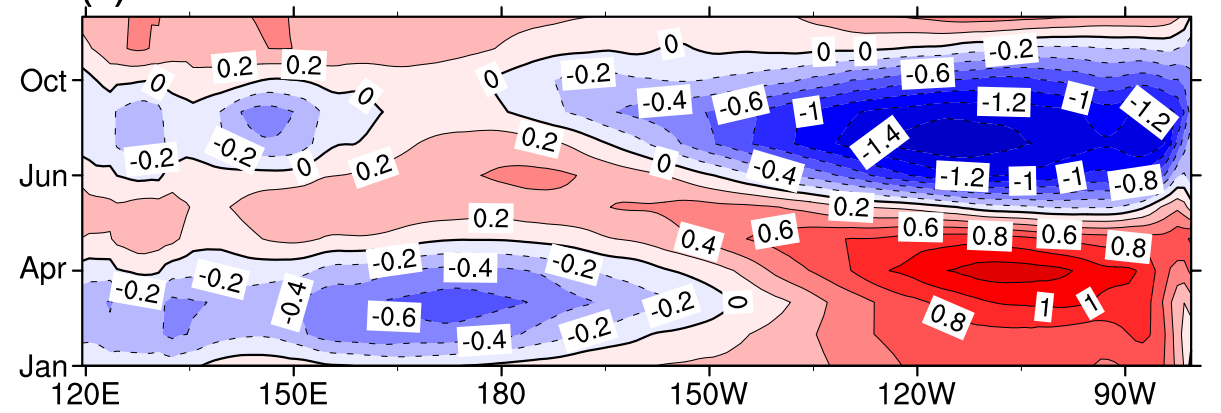

(c) FIO-ESM v1.0 - ERSST

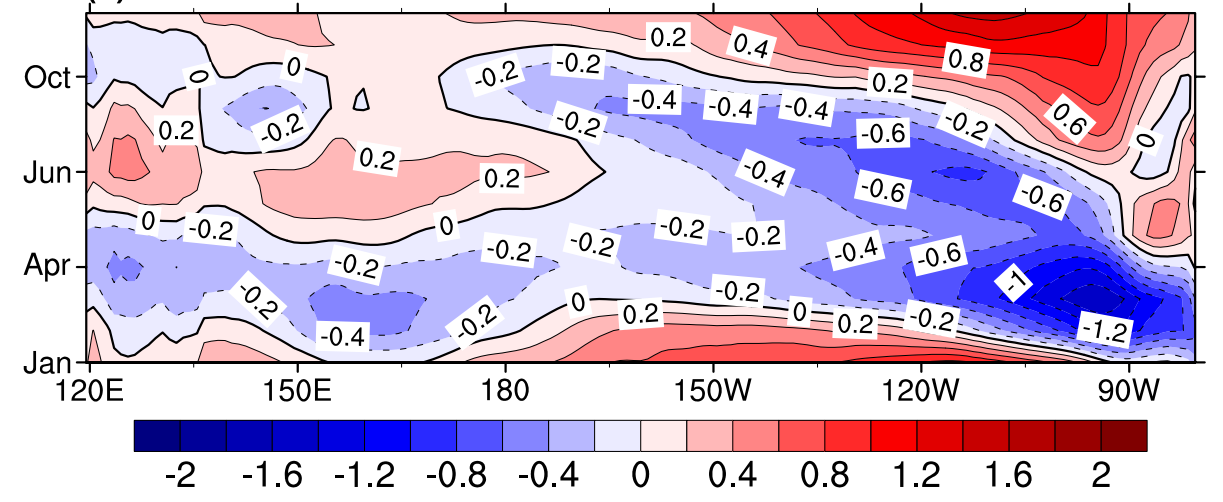


(a) SSTA, ${ }^{\circ} \mathrm{C}$, Aborted

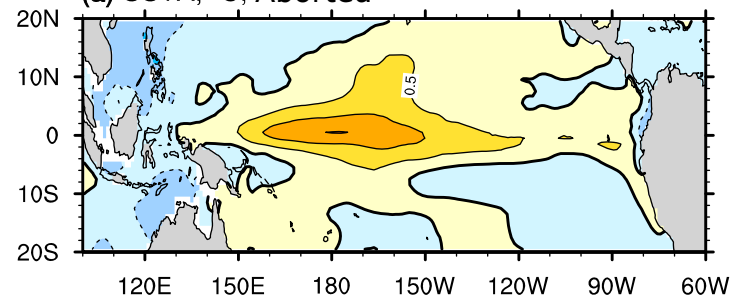

(c) Mix Layer Depth, $\mathrm{m}$

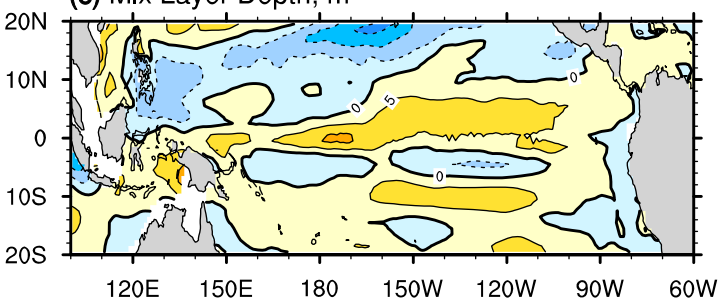

(e) U-Wind Stress, $0.01 \mathrm{~N} / \mathrm{m}^{2}$
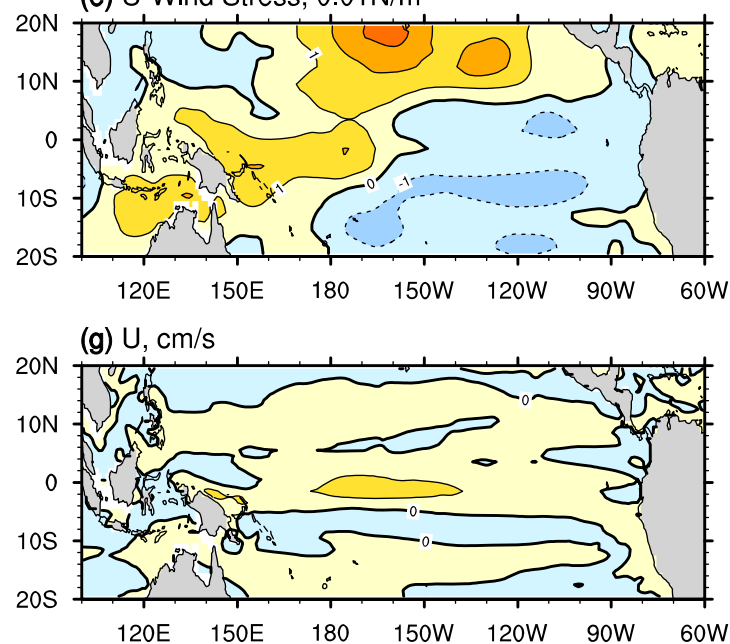

(i) $\mathrm{W}, \mathrm{cm} /$ day

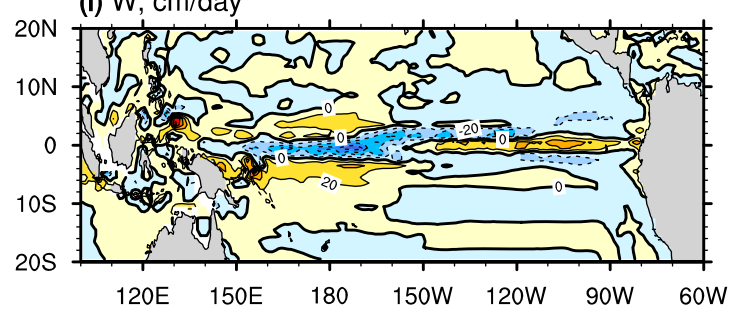

Fig. 9 Anomalous summer and winter El Niño composites [average for $\operatorname{Jan}(0)$ to $\operatorname{Mar}(0)]$. a, b Denote SST, (c) and (d) denote the mixedlayer depths, (e) and (f) denote zonal wind stress, (g) and (h) denote zonal ocean currents, and (i) and (j) denote oceanic vertical velocity.

\section{Summary and discussion}

In this work, FIO-ESM v1.0 El Niño simulations based on its CMIP5 historical experiment outputs were evaluated. One feature of the FIO-ESM $v 1.0$ is the incorporation of the wave-induced mixing into the ocean circulation model. Wave-induced mixing generates warmer SST in the central equatorial Pacific. Mechanisms of SST response (b) SSTA, ${ }^{\circ} \mathrm{C}$, Winter

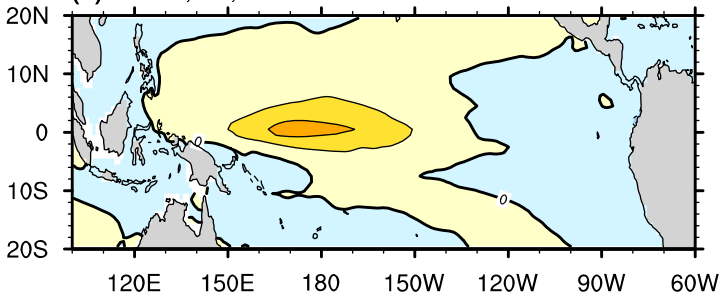

(d) Mix Layer Depth, $\mathrm{m}$

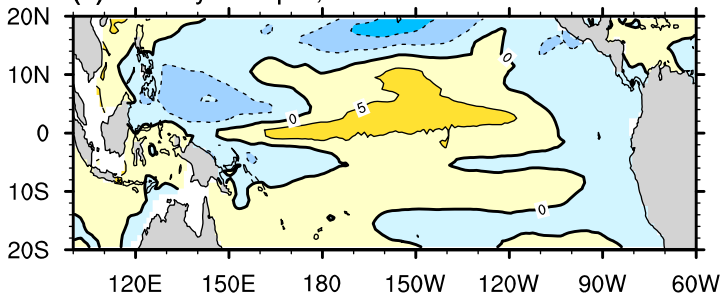

(f) U-Wind Stress, $0.01 \mathrm{~N} / \mathrm{m}^{2}$

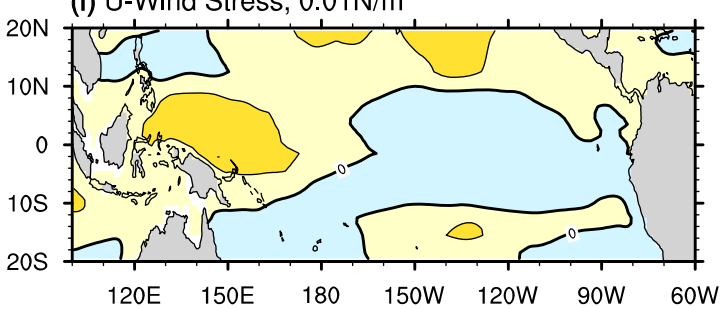

(h) $\mathrm{U}, \mathrm{cm} / \mathrm{s}$

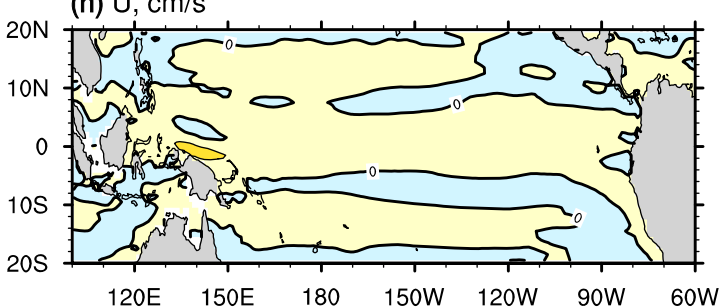

(j) $\mathrm{W}, \mathrm{cm} / \mathrm{day}$

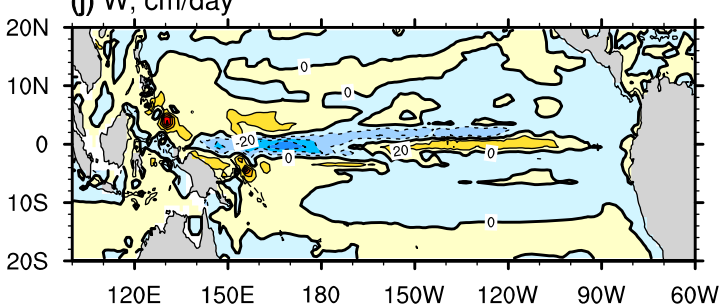

Counter intervals are set to $0.5{ }^{\circ} \mathrm{C}$ in (a) and (b), to $5 \mathrm{~m}$ in (c) and (d), to $0.01 \mathrm{~N} / \mathrm{m}^{2}$ in (e) and (f), to $10 \mathrm{~m} / \mathrm{s}$ in (g) and (h), and to $20 \mathrm{~cm} /$ day $(86,400 * 20 \mathrm{~cm} / \mathrm{s})$ in (i) and (j). The left and right columns refer to Aborted and winter El Niño composites, respectively

to wave-induced mixing are complex, introducing direct and indirect effects of wave-induced mixing into the ocean model, and air-sea interaction processes into the climate system. Wave-induced mixing has a direct cooling effect on SST and deepens mixed layer in general. Especially in the eastern parts of Pacific and Indian Oceans, the cooling effect of the wave-induced mixing is much stronger due to larger waveinduced mixing and a shallower mixed layer than those in 
western and central parts. On the other hand, wave-induced mixing deepens the ocean upper mixed layer, leading to a weakening of zonal surface ocean currents due to larger inertia of upper ocean (Song et al. 2012b) and introducing a less pronounced cooling effect of subsurface entrained waters into the mixed layer (Gao and Zhang 2017), which results in warmer SST tendency in the tropical ocean. Therefore, with the effect of two aspects, SST tends to be warmer in the central Pacific, while colder in the eastern Pacific and Indian Oceans. In turn, pattern of scolder-warmer-colder SST from the eastern Indian Ocean to the eastern Pacific, is amplified due to Bjernkes feedback in the climate system. As a result, unlike what is shown by other CMIP5 models, there is a warm bias in the central-eastern equatorial Pacific in the FIO-ESM v1.0, whereas other models tend to present a cold bias.

As a consequence, although FIO-ESM v1.0 can capture the basic features of El Niño events, it suffers from several simulation problems related to mean states, including eastward shifts in the central locations of El Niño events, narrow spectral ranges with peak occurring over roughly 3 years, excessively strong El Niño events, spurious eastward propagation, and Aborted El Niño events. El Niño composites and mixed-layer heat budgets were used to understand the causes of these simulation biases. A brief summary of our bias analyses is given below:

1. Eastward shifts in the central locations of El Niño events: Weaker simulated trade wind and eastward location shifts in Walker circulation associated with a warm SST bias in the eastern Pacific and a cold SST bias in the western and central Pacific enhanced anomalous westerly wind and eastward tendencies of central locations of Walker circulation by the Bjerknes positive feedback in the onset phase. Thus, the simulated central location of El Niño events appeared $15^{\circ}$ east of the observed location. And as a result, only EP El Niño and no CP El Niño events are simulated in FIO-ESM v1.0.

2. Regular periods of roughly 3 years: Mixed-layer heat budget results demonstrated that the simulated El Niño events involved zonal advective feedback and thermocline feedback, with a spectral peak at 3 years. The simulated zonal advective feedback is the main process shaping both the development and mature phases because of the enhanced zonal current associated with stronger anomalous westerly winds and shallower anomalous mixed-layer depth due to deeper climatological mixedlayer depth in the eastern Pacific. The simulated thermocline feedback played an important role during the El Niño onset phase due to the shallow climatological mixed-layer depth related to the cold SST biases in the western and central Pacific. The mechanism for period of simulated ENSO is complex for CGCMs and need be analyzed further in the future.

3. Excessively strong El Niño events: Warmer mean states leads to stronger ENSO events. Three processes primarily contributed to the larger amplitudes of El Niño events in the model. The first was a warmer SST bias in the equatorial Pacific amplified by the Bjerknes positive feedback. The second involved the transport of warmer water with stronger zonal advective feedback taking the warmer water from the western Pacific in the model, and the meridional transport from the southeastern and northeastern Pacific off the equator with a warm SST bias. The third involved Ekman feedback transporting warmer water from the subsurface by upwelling due to the deeper climatological mixed-layer depth in the eastern Pacific. Surface heat flux feedback always mitigates the amplitude of an increasing SST.

4. Spurious eastward propagation: Thermocline feedback is the main process in the El Niño onset phase $(\operatorname{Jan}(0)$ to $\operatorname{Mar}(0))$ and in the first 3 months of the development phase $(\operatorname{Apr}(0)$ to Jun( $(0))$; the time lag between thermocline feedback and zonal advective feedback is 6 months in FIO-ESM v1.0, which is longer than that derived from observations. Therefore, the simulated El Niño events tended to exhibit eastward propagation driven by the thermocline feedback, and the eastward shifting of the central locations of El Niño events also contributed to the eastward propagation.

5. Aborted El Niño events: The analysis shows that two simulated biases mainly contributed to the Aborted El Niño events in FIO-ESM v1.0. One relates to the double ITCZ problem (a warm SST bias over the southeastern Pacific), An excessively strong and zonal Southern Convergence Zone can enhance the climatological meridional current transport and can trigger an Aborted El Niño event. Another factor relates to the weaker seasonal cycle of eastern equatorial Pacific SST. The cold SST bias related to the simulated weaker annual cycle tends to trigger a stronger SSTA in the onset phase. The contributions of the two simulated biases to Aborted El Niño events will be examined in further studies.

La Niña events, cold events of ENSO, exhibited similar simulation problems to El Niño events in FIO-ESM v1.0. For example, the SSTAs of most of the simulated La Niña events (nine out of 12 ) were greater than $2{ }^{\circ} \mathrm{C}$ with the largest exceeding $3{ }^{\circ} \mathrm{C}$ (Fig. 1d, blue bar), while all the SSTAs of observed La Niña events were less than $1.5^{\circ} \mathrm{C}$ (Fig. 1c, blue bar). Four out of $12 \mathrm{La}$ Niña events with their phases locked to spring or summer in the FIO-ESM v.1.0. As these simulated biases of the La Niña events can be attributed to the same mechanisms of the El Niño events through the 
mixed-layer heat budget (Fig. 10), so we do not discuss them here in detail.

In addition to the simulated ENSO biases, El Niño and La Niña symmetry is also a problem in FIO-ESM v1.0. The amplitude of the observed El Niño events is much larger than that of the observed La Niña events (Fig. 1c), showing that the El Niño and La Niña events are asymmetric in the observations. However, El Niño and La Niña events simulated by FIO-ESM v1.0 are symmetric (Fig. 1d). The mixed-layer heat budget results showed the damping effect of heat flux on La Niña events (Fig. 10e, black line) to be only half of that on El Niño events (Fig. 6e, black line). A further decomposition of heat budget analysis demonstrated that the SST-cloud-shortwave radiation feedback mainly contributed to the damping effect differences between El Niño events (Fig. 6e, blue line) and La Niña events (Fig. 10e, blue line). Despite the difference in SST-cloud-shortwave radiation feedback, the features of the other feedbacks for La Niña events (Fig. 10) are generally similar to those for El Niño events (Fig. 6).

In addition to the simulated ENSO symmetry related to the SST-cloud-shortwave radiation feedback, the above analyses indicate that the simulated El Niño biases are associated with mean state biases, such as a warm SST bias in
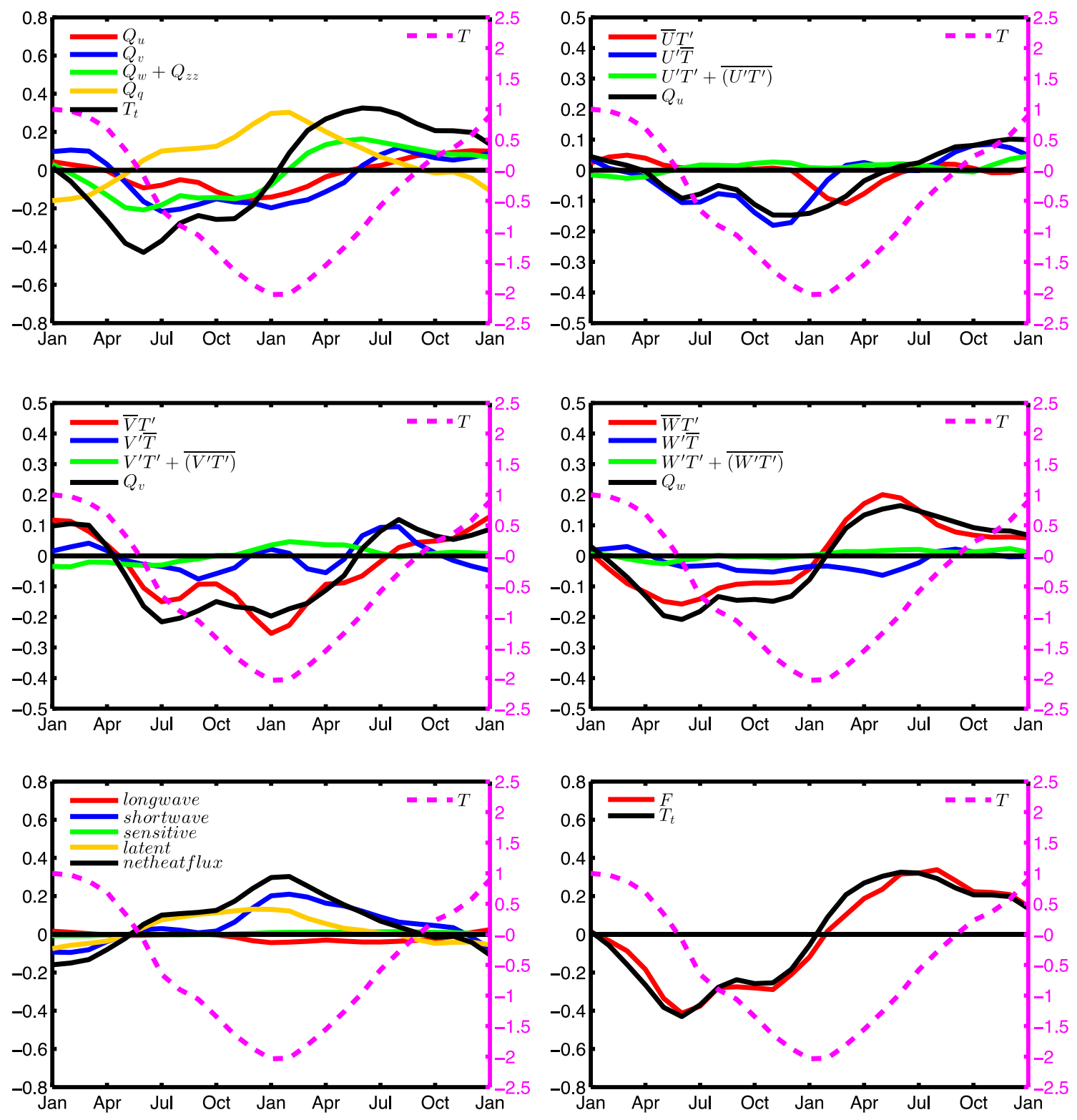

Fig. 10 Anomalous heat budget of the La Niña composite of the Niño 3 region $\left(90^{\circ}-150^{\circ} \mathrm{W}, 5^{\circ} \mathrm{S}-5^{\circ} \mathrm{N}\right)$. a Heat budget $\left({ }^{\circ} \mathrm{C} / \mathrm{month}\right)$. Decomposition of (b) zonal advection, (c) meridional advection, (d) vertical

advection and diffusion, (e) net surface heat flux, and (f) heat budget closure. Temperatures are plotted on the scale of the right axis 
the central-eastern Pacific and a cold SST bias in the western Pacific, seasonal cycles of SST in the equatorial eastern Pacific, and the weaker trade winds. This suggests that the improvement of ENSO simulations may be still focused on the mean states in the tropical region.

Acknowledgements We acknowledge four anonymous reviewers for their constructive comments and recommendations on ways of improving the manuscript. We would also like to thank Boyin Huang for his valuable suggestions on the heat budget analysis. This work was partially supported by the National Key R\&D Program of China (2018YFB0505000 and 2016YFE0101400) and the National Natural Science Foundation of China (41476023). Ying Bao's work was supported by the East Asia Marine Cooperation Platform of ChinaASEAN Maritime Cooperation Fund (YZ0416001) and the ChinaKorea Cooperation Project on the Northwestern Pacific Climate Change and Its Prediction. Zhenya Song's work was supported by the Basic Scientific Fund for National Public Research Institute of China (2016S03) and the AoShan Talents Cultivation Excellent Scholar Program of Qingdao National Laboratory for Marine Science and Technology (2017ASTCP-ES04).

Open Access This article is distributed under the terms of the Creative Commons Attribution 4.0 International License (http://creativeco mmons.org/licenses/by/4.0/), which permits unrestricted use, distribution, and reproduction in any medium, provided you give appropriate credit to the original author(s) and the source, provide a link to the Creative Commons license, and indicate if changes were made.

\section{References}

Alexander MA, Blade I, Newman M et al (2002) The atmospheric bridge: the influence of ENSO teleconnections on air-sea interaction over the global oceans. J Clim 15(16):2205-2231

Behringer DW, Xue Y (2004) Evaluation of the global ocean data assimilation system at NCEP: The Pacific Ocean. In: Eighth symp. on integrated observing and assimilation systems for atmosphere, oceans, and land surface, AMS 84th annual meeting, Seattle, WA, $11-15$

Bellenger H, Guilyardi E, Leloup J et al (2014) ENSO representation in climate models: from CMIP3 to CMIP5. Clim Dyn 42:1999-2018

Blanke B, Neelin JD, Gutzler D (1997) Estimating the effects of stochastic wind stress forcing on ENSO irregularity. J Clim 10:1473-1486

Chang P, Ji L, Li H et al (1996) Chaotic dynamics versus stochastic processed in El Niño-Southern Oscillation in coupled oceanatmosphere model. Physical D 98:301-320

Collins WD, Rasch PJ, Boville BA et al (2006) The formulation and atmospheric simulation of the Community Atmosphere Model version 3 (CAM3). J Clim 19(11):2144-2161

Fang X-H, Zheng F, Zhu J (2015) The cloud radiative effect when simulating strength asymmetry in two types of El Niño events using CMIP5 models. J Geophys Res 120(6):4357-4369. https:// doi.org/10.1002/2014JC010683

Feng J, Chen W, Gong H et al (2019) An investigation of CMIP5 model biases in simulating the impacts of central Pacific El Niño on the East Asian summer monsoon. Clim Dyn 52:2631-2645. https:// doi.org/10.1007/s00382-018-4284-2

Flato G, Marotzke J, Abiodun B et al (2013) Evaluation of Climate Models. In: Stocker TF, Qin D, Plattner G-K et al (eds) Climate change 2013: the physical science basis. contribution of working group I to the fifth assessment report of the intergovernmental panel on climate change. Cambridge Univ. Press, Cambridge, pp $741-866$

Gao C, Zhang R-H (2017) The roles of atmospheric wind and entrained water temperature (Te) in the second-year cooling of the 2010-12 La Niña event. Clim Dyn 48:597-617. https://doi.org/10.1007/ s00382-016-3097-4

Glantz MH (2001) Currents of change: impacts of El Niño and La Niña on climate and society. Cambridge Univ. Press, Cambridge

Good SA, Martin MJ, Rayner NA (2013) EN4: quality controlled ocean temperature and salinity profiles and monthly objective analyses with uncertainty estimates. J Geophys Res Oceans 118:6704-6716. https://doi.org/10.1002/2013JC009067

Graham FS, Wittenberg AT, Brown JN et al (2017) Understanding the double peaked El Niño in coupled GCMs. Clim Dyn 48:2045-2063. https://doi.org/10.1007/s00382-016-3189-1

Guilyardi E, Delecluse P, Gualdi S et al (2003) Mechanisms for ENSO phase change in a coupled GCM. J Clim 16:1141-1158

Huang B, Xue Y, Zhang D et al (2010) The NCEP GODAS ocean analysis of the tropical pacific mixed layer heat budget on seasonal to interannual time scales. J Clim 23:4901-4925. https:// doi.org/10.1175/2010JCLI3373.1

Huang B, Thorne P, Smith T et al (2015) Further exploring and quantifying uncertainties for extended reconstructed sea surface temperature (ERSST) version 4 (v4). J Clim 29:3119-3142. https://doi.org/10.1175/JCLI-D-15-0430.1

Hunke EC, Lipscomb WH (2008) CICE: The Los Alamos sea ice model. Documentation and software user's manual. Version 4.0. Technical Report LA-CC-06-012. Los Alamos National Laboratory, Los Alamos, NM

Jin FF (1996) Tropical ocean-atmosphere interaction, the Pacific cold tongue, and the El Niño-Southern oscillation. Science 274:76-78

Jin FF (1997) An equatorial ocean recharge paradigm for ENSO. Part I: conceptual model. J Atmos Sci 54:811-829

Kalnay E, Kanamitsu M, Kistler R et al (1996) The NCEP/NCAR 40-year reanalysis project. Bull Amer Meteor Soc 77:437-470. https://doi.org/10.1175/1520-0477(1996)077\%3c0437:TNYRP $\% 3$ e2.0.CO;2

Liu L, Xie S-P, Zheng X-T et al (2014) Indian Ocean variability in the CMIP5 multi-model ensemble: the zonal dipole model. Clim Dyn 43(5-6): 1715-1730

Lloyd J, Guilyardi E, Weller H (2012) The role of atmosphere feedbacks during ENSO in the CMIP3 models. Part III: the shortwave flux feedback. J Clim 25:4275-4293. https://doi.org/10.1175/ JCLI-D-11-00178.1

Manabe S, Bryan K (1969) Climate calculations with a combined ocean-atmosphere model. J Atmos Sci 26:786-789

Matveeva T, Gushchina D, Dewitte B (2018) The seasonal relationship between intraseasonal tropical variability and ENSO in CMIP5. Geosci Model Dev 11:2372-2392. https://doi.org/10.5194/ gmd-11-2373-2018

McPhaden MJ, Glantz MH (2006) ENSO as an integrating concept in earth science. Science 314:1740-1745

McPhaden MJ, Hayus DP, Mangum LJ et al (1990) Variability in the western equatorial pacific ocean during the 1986-87 El Niño/ southern oscillation event. J Phys Oceanogr 20:190-208

Murphy BF, Ye H, Delage F (2015) Impacts of variations in the strength and structure of El Niño events on Pacific rainfall in CMIP5 models. Clim Dyn 44:3171-3186. https://doi.org/10.1007/ s00382-014-2389-9

Neelin JD, Jin F, Syu H (2000) Variations in ENSO phase locking. J Clim 13:2570-2590

Oleson KW, Niu G-Y, Yang Z-L et al (2008) Improvements to the community land model and their impact on the hydrological cycle. $\mathrm{J}$ Geophys Res 113:G01021. https://doi.org/10.1029/2007JG000563 
Philander SGH (1983) El Niño-Southern oscillation phenomena. Nature 302(5906):295-301

Philander SGH (1990) El Niño, La Niña, and the southern oscillation. Acad Press, London

Qiao FL, Song ZY, Bao Y et al (2013) Development and evaluation of an Earth System Model with surface gravity waves. J Geophys Res Oceans 118:4514-4524. https://doi.org/10.1002/jgrc.20327

Rasmusson EM, Wallace JM (1983) Meteorological aspects of the El Niño/Southern oscillation. Science 222:1195-1202. https://doi. org/10.1126/science.222.4629.1195

Roy I, Gagnon AS, Siingh D (2019) Evaluating ENSO teleconnections using observations and CMIP5 models. Theor Appl Climatol 136(3-4):1085-1098. https://doi.org/10.1007/s00704-018-2536-z

Sarachik ES, Cane MA (2010) The El Niño-Southern oscillation phenomenon. Cambridge Univ Press, Cambridge, p 384

Smith R, Jones P, Briegleb B, et al (2010) The parallel ocean program (POP) reference manual, ocean component of the community climate system model (CCSM). Technical Report LAUR-10-01853. National Central for Atmosphere Research, Boulder, CO

Song Z, Qiao F, Lei X, Wang C (2012a) Influence of parallel computational uncertainty on simulations of the coupled general climate model. Geosci Model Dev 5:313-319. https://doi.org/10.5194/ gmd-5-313-2012

Song Z, Qiao F, Song Y (2012b) Response of the equatorial basinwide SST to non-breaking surface wave-induced mixing in a climate model: An amendment to tropical bias. J Geophys Res 117:C00J26. https://doi.org/10.1029/2012JC007931

Song Z, Liu H, Wang C et al (2014) Evaluation of the eastern equatorial pacific SST seasonal cycle in CMIP5 models. Ocean Sci 10(5):837-843. https://doi.org/10.5194/os-10-837-2014

Song Z, Shu Q, Bao Y et al (2015) The prediction on the 2015/16 El Niño event from the perspective of FIO-ESM. Acta Oceanol Sin 34(12):67-71. https://doi.org/10.1007/s13131-015-0787-4

Taschetto AS, Sen Gupta A, Jourdain NC, Santoso A (2014) Cold tongue and warm pool ENSO events in CMIP5: mean state and future projections. J Clim 27:2861-2885. https://doi.org/10.1175/ JCLI-D-13-00437.1
Wang CZ, Picaut J (2004) Understanding ENSO physics-a review. In: Wang CZ, Xie SP, Carton JA (eds) Earth's climate: the oceanatmosphere interaction. AGU, Washington, pp 21-48. https://doi. org/10.1029/147GM02

Wang H, He S, Liu J (2013) Present and future relationship between the East Asian winter monsoon and ENSO: results of CMIP5. J Geophys Res Oceans 118:5222-5237. https://doi.org/10.1002/ jgrc.20332

Webster PJ, Yang S (1992) Monsoon and ENSO: selectively interactive systems. Q J Roy Meteorol Soc 118(507):877-926

Xie S-P, Pahilander SGH (1994) A coupled ocean-atmosphere model of relevance to the ITCZ in the eastern Pacific. Tellus 46A:340-350. https://doi.org/10.1034/j.1600-0870.1994.t01-1-00001.x

Xu K, Tam C-Y, Zhu C et al (2017) CMIP5 projections of two types of El Niño and their related tropical precipitation in the twentyfirst century. J Clim 30:849-864. https://doi.org/10.1175/ JCLI-D-16-0413.1

Yang Y, Qiao F, Zhao W (2005) MASNUM ocean wave numerical model in spherical coordinates and its application. Acta Oceanol Sin 27(2):1-7. https://doi.org/10.1111/j.1745-7254.2005.00209 .$x$ (in Chinese)

Yun K-S, Yeh S-W, Ha K-J (2016) Inter-El Niño variability in CMIP5 models: model deficiencies and future changes. J Geophys Res Atmos 121:3894-3906. https://doi.org/10.1002/2016JD024964

Zheng W, Yu Y (2007) ENSO phase-locking in an ocean-atmosphere coupled model FGCM-1.0. Adv Atmos Sci 24(5):833-844. https ://doi.org/10.1007/s00376-007-0833-z

Zheng F, Zhang W, Yu J-Y et al (2015) A possible bias of simulating the post-2000 changing ENSO. Sci Bull 60(21):1850-1857. https ://doi.org/10.1007/s11434-015-0912-y

Publisher's Note Springer Nature remains neutral with regard to jurisdictional claims in published maps and institutional affiliations. 